\title{
Arabic Language Teachers' Perceptions of a Standards-based Educational Reform in the UAEpath
}

Corresponding Author:

Mariam Alhashmi;

email:

Mariam.alhashmi@zu.ac.ae

Submitted: April 13, 2021

Accepted: September 8, 2021

Published: January 31, 2022

Production and Hosting by Knowledge E

(c) Mariam Alhashmi et

al. This article is distributed under the terms of the

Creative Commons

Attribution License, which

permits unrestricted use and redistribution provided that the original author and source are credited.

Managing Editor:

Natasha Mansur

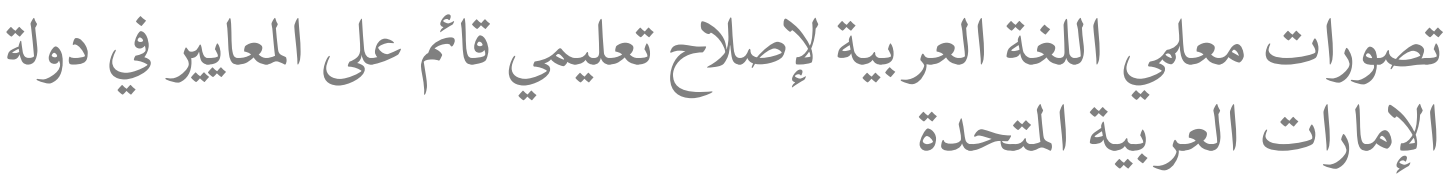

Mariam Alhashmi1*, Hanada Taha-Thomure1, Karima Almazroui ${ }^{2}$

${ }^{1}$ College of Education, Zayed University, Abu Dhabi, United Arab Emirates

${ }^{2}$ Mohammad Bin Zayed University for Humanities, Abu Dhabi, United Arab Emirates

\section{ORCID}

Mariam Alhashmi: https://orcid.org/0000-0003-3294-9424

Hanada Taha-Thomure: https://orcid.org/0000-0003-4111-0

Karima Almazroui: https://orcid.org/0000-0002-3738-1033

\section{Abstract}

Arabic language curriculum has been undergoing reforms across the Arab world to improve Arab students' acquisition of their first language. Reform initiatives including internationally funded projects have been aimed recently at reforming and modernizing the teaching and learning of the Arabic language. Many Arab countries have adopted a standardsbased instruction model. However, there is a lack of vision regarding how this model can be successfully implemented at a national level. This article examines how standardsbased curricular mandates have been translated into practice and how teachers perceive implementing the standards-based Arabic curriculum in public schools in Abu Dhabi. The study employs qualitative purposeful sampling and an exploratory methodology to collect experiences of Arabic teachers who implemented the curriculum from 2010 to 2017. The findings of the study uncover the main characteristics, successes, and challenges of the standards-based teaching model as perceived by teachers. The findings also display a consensus for implementing the standards-based Arabic curriculum among teachers. Additionally, the findings show that the educational model requires intense professional development that is rigorous, continuous and collaborative, mentorship and coaching in the classroom, integrated reformative efforts to change ineffective pedagogical practices and capacity building in the UAE.

| (الملخمن

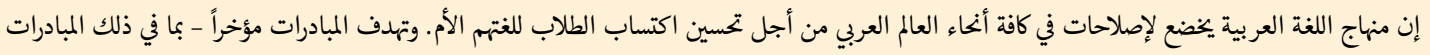

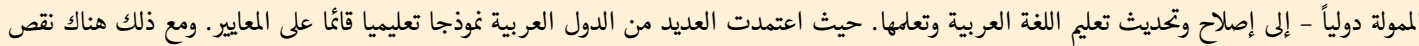

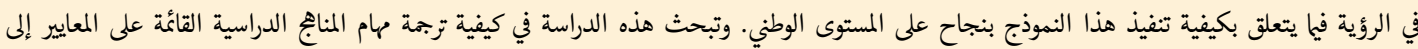

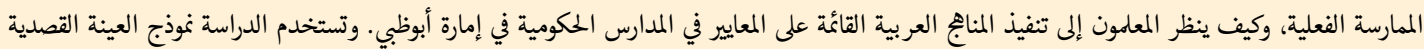

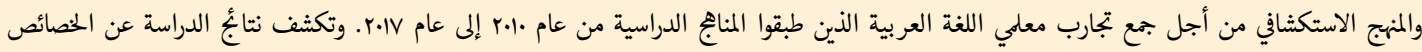

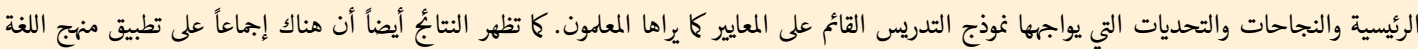

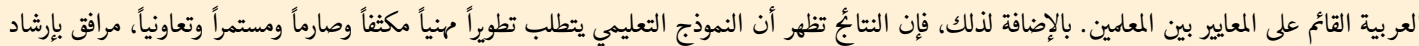

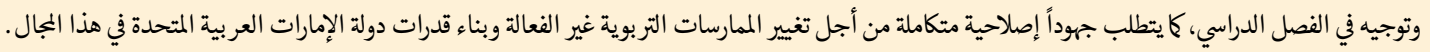


Keywords: Arabic curriculum, Educational reform, Standards-based curriculum, Teacher views, United Arab Emirates

الكالمات المفتاحية: المنهاج العربي، الإصلاح التربوي، المنهاج القائم على المعايير، آراء المعلم، الإمارات العربية المتحدة.

\section{Introduction}

In the past three decades, the Arab world has witnessed a rise in literacy levels, as a result of which millions of youths in the region have gained access to education. As substantiated by a recent report from the United Nations Educational, Scientific and Cultural Organization (UNESCO, 2017), 89.6\% of Arab youth aged 15-24 years are literate. In contrast, the literacy rate of those over 65 years is as low as $39.1 \%$ (UNESCO, 2017). However, the quality of education in the Arab world has not been suitable for survival and competition globally that is becoming increasingly automated, connected, and intelligent (Faour, 2012). Results of international standardized tests in math, science, and literacy often draw a grim picture of education quality in the Arab world. Students in Arab countries taking these tests, such as the Trends in International Mathematics and Science Study, Progress in International Reading Literacy Study, and Program for International Student Assessment, have consistently scored lower than and ranked below the world average (World Bank, 2021). Reports analyzing the results of these tests point to students reflecting a lack of higher thinking skills and weakness in analytical and point to students' lack of higher order thinking skills (Mullis \& Arora, 2012; Mullis et al., 2012), all of which are key to employment in the $21^{\text {st }}$ century and necessary for economic survival (Karoly, 2010; World Bank, 2004).

Standards-based education is a core idea guiding education policy and reform globally in recent decades. While standards-based instruction improves teachers' instruction and students' learning through coherent content standards in core academic subjects, the debates around the vision, efficacy, and implementation of standards-based instruction continue (Polikoff et al, 2016; Porter et al., 2009). The standards-based curricular conversation is not new to the Arab world, and many Arabic language curricular changes toward a standards-based model were implemented in several Arab countries (TahaThomure \& Speaker, 2018). However, to date, there is no clear vision of how this approach was perceived by teachers and instructors and, more importantly, how this model would be implemented on a national level. Studies on the conceptualization 
and implementation of the standards-based curriculum in the Arab region are limited, and decisions to adopt, implement and/or even reject the use of standards do not seem to be based on empirical data (Taha-Thomure \& Speaker, 2018). This study examines some of the unanswered questions about the standards movement and the implementation of Arabic language standards in the context of public schools in Abu Dhabi, UAE. The study also investigates the Arabic teachers' perceptions toward the standards-based curriculum, the challenges, and the successes that accompanied its implementation.

\subsection{Context of the study and research objectives}

The study was conducted in Abu Dhabi, UAE. The Abu Dhabi Department of Education and Knowledge (ADEK) serves over 136,600 students in 256 public schools, including 55 kindergartens, 74 primary, 44 middle schools, and 83 secondary schools (ADEK, 2021). According to the ADEK, the educational districts in Abu Dhabi are divided into three regions: Abu Dhabi, Al Ain, and Al Dhafra. In the 2013-2014 academic year, Abu Dhabi, Al Ain, and Al Dhafra regions accounted for 45.3\%, 45\%, and $9.7 \%$ of 10,997 public school teachers, respectively, of whom $69 \%$ were females and $31 \%$ males. Nearly $81 \%$ of these teachers had a bachelor's degree, and $19 \%$ had a master's or a doctoral degree. Teachers from the UAE, Arab nations, and Western nations represented $37.6 \%, 38.8 \%$, and $21.4 \%$ of the total public teaching workforce, respectively, while the remaining $2.2 \%$ were expatriates of other nationalities.

In its transformation of P-12 education, ADEK revamped the curriculum, pedagogy, school inspection system, and teacher recruitment and development processes across all public schools. These were among other quality improvement initiatives to raise the effectiveness of school teaching (ADEK, 2021). For the teaching of Arabic, a standardsbased curriculum was rolled out in the academic year 2011-2012, emphasizing a literacy-based balanced approach. To support the implementation of this curriculum, Arabic textbooks were revamped, and efforts were made to make authentic children's literature in Arabic available in schools. The goal of helping every student achieve fluency in Arabic reading and writing by the time they graduate from Grade 12 was seriously pursued (Hussein, 2014; Taha-Thomure, 2019). To support this priority, ADEK also rolled out professional development programs for teachers and developed curricular support materials for teachers, parents, and students (Badri et al., 2016). 
The reformation of the Arabic language curriculum initiated in Abu Dhabi from 2010 to 2017 provided a unique opportunity to study teachers' views on the reform. Specifically, this study answers three research questions:

(1) How do Arabic teachers perceive the Arabic standards-based curriculum?

(2) What are the challenges that the study respondents faced during the transition to the standards-based curriculum?

(3) What are the successes that the teachers have experienced while implementing the standards-based curriculum?

\section{Literature Review}

\subsection{Standards-based instruction}

A standards-based approach does not compare students' grades. Instead, it measures the progress in their learning against consistent and reliable standards that do not change with the change of schools, textbooks, or teachers (Carr \& Harris, 2001; Chambers \& Dean, 2000; Reeves, 2004). The United States' shift to the standards-based approach in the late 1980s was steeped in a theory that holds that all students are capable of learning, although they might do so at varying paces, and focused on what students learned rather than on when they learned it (Chambers \& Dean, 2000; Ogawa et al., 2004). Studies show that pedagogy employing a standards-based approach helped students achieve more than students taught by the textbook-based approach and confirm the positive gains of test-based accountability in general (Carnoy \& Loeb, 2002; Hanushek \& Raymond, 2005). For instance, in some schools in Lake Havasu City, there was a $15 \%$ increase in students' achievement rates in reading after a year of adopting standards-based instruction (Stecher et al., 2000). Significantly positive results were achieved in schools where the curriculum was better aligned with the standards model, and teachers were more engaged (Stecher et al., 2000).

In the Arab world, Arabic has been the language of instruction in most public schools (United Arab Emirates Ministry of Culture and Youth, 2020). For as long as there has been formal schooling, Arabic has been taught in a didactic manner that is teacher-centered, textbook-based, and grammar-heavy (Taha-Thomure, 2008). Arabic language textbooks are perceived and utilized as the sole source of educational planning, instruction, and assessment (Faour, 2012; Taha-Thomure, 2017). In the past decade, some promising initiatives focusing on improving and modernizing Arabic language teaching in the Arab world have been taken (World Bank, 2021). Content standards for the Arabic language 
have been developed and adopted by several Arab countries (Taha-Thomure \& Speaker, 2018).

The standards movement in the Arab world has been an inconsistent trend that started in 2000 with Qatar's adoption of standards, followed by the UAE in 2010 and Saudi Arabia and Jordan in 2018 (Taha-Thomure \& Speaker, 2018).

The UAE spearheaded several Arabic language initiatives, including an Arabic Language Charter (Taha-Thomure, 2019) and the Arabic Reading Challenge in which more than six million children and young adults around the world have participated (World Bank, 2021). The UAE also introduced a Reading Law in 2016 that requires schools, universities, and public libraries to increase their annual collections of books (Salama, 2016). The law requires all employers to allow employees time to read during the workday and treat all reading "goods" and material as tax-exempt. The law also mandated that one month per year would be dedicated as a "month of reading" across the UAE. Consequently, all governmental entities host reading activities that benefit their employees and the community. These initiatives, including the move to a standardsbased approach, have shaped debates on how best to improve teaching and learning of the Arabic language. Another urgent issue debated at the region's educational conferences is Arabic language teachers' willingness to give up some of their authority in the classroom while making the shift from a teacher-centered and textbook-based mode of instruction to standards-based instruction.

The debates and research around the implementation of standards-based instruction seem to have matured in some countries, including the United States of America where the Common Core State Standards were introduced in 2009 as an answer to a schooling system that needed to do more to address student achievement and preparedness for college and careers (Halladay \& Moses, 2013). Debates on pressing issues linked to common core state standards, including training and support of teachers, their autonomy, and linear learning versus recursive progression, are still taking place (Barlow, 2012; Morgan, 2017; National Research Council, 2008; Polikoff et al., 2016; Porter et al., 2009; Stecher et al., 2000).

However, few studies have been conducted on the subject in an Arab context (Faour, 2012; Taha-Thomure, 2008; Taha-Thomure \& Speaker, 2018). Although some Arab countries might have articulated standards documents, implementation of the approach remains unaligned with the stated standards (Taha-Thomure \& Sabella, 2015). To address these gaps in research and action, this study explores how standards-based curricular mandates have been translated into practice and how they were interpreted 
and implemented by Arabic language teachers within the context of the Emirate of Abu Dhabi.

\section{Methodology}

\subsection{Study design}

Considering the novelty of the education system in the UAE and its recent curricular reform, a qualitative exploratory methodological approach was used. This approach allowed researchers to gather primary school Arabic language teachers' perceptions and experiences about the Arabic standards-based curriculum implemented between 2010 and 2017. Focus groups, commonly used to conduct an in-depth exploration of a topic (Stewart et al., 2000), were used to examine the implementation of the standards-based curriculum in Abu Dhabi, about which little is known. This method's advantage over observations, one-to-one interviews, or questionnaire surveys is that it reveals the participants' attitudes, emotions, beliefs, experiences, and reactions in ways that the other methods do not (Gibbs, 1997). Additionally, focus group discussions enabled Arabic teachers to discuss their experiences and perceptions in the presence of colleagues who shared similar experiences.

\subsection{Participants}

Participants for this study were drawn from a pool of 3,357 public school teachers in Abu Dhabi, who taught Cycle 1 primary (grades one to five). They were selected based on a purposive sampling technique to collect rich and in-depth information (Merriam, 2009). ADEK nominated the schools that participated in this study. These schools had successfully implemented the Arabic standards-based curriculum and had the potential to provide valuable data.

Ten primary school principals in the Emirate of Abu Dhabi were sent a formal letter explaining the study's purpose and requesting permission to visit their respective schools to conduct focus group interviews. School principals were asked to nominate five teachers who had five or more years of experience teaching the Arabic standardsbased curriculum and were working in a government primary school. Thus, 29 teachers participated in five focus groups. Most participants $(n=26)$ were Emirati. Participants ranged in age from 35 to 55 years and had an average of 15 years' teaching experience. Twenty-five teachers were females, and four were males. 


\subsection{Materials}

The authors developed 10 open-ended questions to elicit information about the landscape of the reform process. These questions focused on participants' perceptions and experiences while implementing a standards-based Arabic curriculum in their respective schools. Questions ranged from demographic ones to those related to personal behaviors, opinions, values, feelings, and knowledge, as recommended by Merriam (2009).

The focus group questions were divided into four main categories: (1) teachers' understanding of the standards-based curriculum; (2) teachers' attitudes towards the curriculum's impact on students' achievements; (3) challenges teachers faced while implementing the curriculum; and (4) impact on teachers' competencies pertaining to teaching Arabic. To see the range of questions asked in the focus groups, please refer to Appendix A.

\subsection{Procedures}

Ethical approvals for this research were obtained from the ethics committee of the first author's university and from ADEK. The focus groups were hosted in two schools, one located in Abu Dhabi and the other in Al Ain. All participants signed consent forms to ensure the confidentiality of information shared and allow researchers to audio-record the discussions.

Each focus group discussion lasted approximately $50 \mathrm{~min}$. While the protocol of preconceived questions was used to help direct the discussion, a semi-structured format was applied to give teachers the freedom to discuss anything they thought was relevant to the topic. A trained research assistant moderated the group discussion, and another research assistant took notes and occasionally asked clarificatory questions. The order of participants answering each question was constantly changed to allow participants a fair opportunity to express themselves, to reduce the bias that could have been caused by strongly opinionated members, and to reduce the pressure on participants to always answer first (Stewart et al., 2007).

\subsection{Data analysis}

The focus groups' audio files were fully transcribed to provide a rigorous and productive basis for the analysis. The focus groups' transcriptions totaled 85 pages. Two researchers independently coded the focus groups' transcripts and agreed on a unified 
codebook of themes. The researchers followed a content analysis approach based on the steps identified by Litosseliti (2003). An inductive approach enabled authors to identify and define relevant themes from the raw data set authentically and reliably through content analysis.

First, the researchers read the transcripts for general impressions. Second, they identified the substantive points in the discussions and categorized them. Third, they looked for the most important themes, issues, ideas, and new topics or issues emerging from the discussions. The researchers also searched for trends and patterns in each discussion, and similarities and differences across the focus groups on each topic. Themes and sub-themes emerged through the cyclical process of coding and analysis (Litosseliti, 2003). Last, the researchers further developed the themes; they were then compared to enhance the trustworthiness of the data through intercoder agreement (Creswell, 2009).

\section{Results}

This study explored the Arabic language teachers' interpretation of their implementation of the standards-based curriculum at the scale of the Emirate of Abu Dhabi. This study revealed how teachers perceived their experiences while implementing the curriculum, the challenges they faced while transitioning to this approach, and the successes they eventually achieved. The findings of this study are presented below under the following four categories that emerged from the inductive content analysis of the data:

(1) the key features of the standards-based curriculum as perceived by the teachers; (2) the standards-based curriculum and content variation; (3) the teacher and the standardsbased curriculum; and (4) the student and the standards-based curriculum.

\subsection{Key features of the standards-based curriculum}

The description of the standards-based curriculum revolved around four emerging themes that resembled its key features. These themes were purposefulness, relevance, quality, and engagement.

Purposefulness refers to the "why" in the learning process and the importance of having students understand each performance indicator and standard they are working toward (Ornstein \& Hunkins, 2017). Participating teachers viewed the standards-based curriculum to be purposeful, with the learning outcomes and objectives clearly known. As a result, the teachers indicated that they knew exactly what to teach during class, 
what the students needed to learn, and the exact academic level the students need to reach. The teachers knew precisely what the students needed to accomplish, and consequently, students knew what skills they needed to acquire. A teacher defined Arabic standards-based curriculum as:

It is the curriculum in which the learning objectives in the form of standards and indicators are identified and made clear to the teacher, the student, and the parent.

The second commonly mentioned feature was the relevance of the curriculum. Relevance refers to learning that is contextualized and suited to students' needs and interests (Ornstein \& Hunkins, 2017). Teachers liked the flexibility and freedom of choice they were given regarding text selection. They enjoyed finding texts that related to the students' interests. Many of these texts were chosen to meet students' needs and addressed the issues they faced in real life. Since the texts were not based on predetermined molds, the teachers described the curriculum as being interactive and responsive to students' live environments.

The emphasis on quality was the third frequently mentioned feature of the implemented curriculum. Most teachers asserted that the standards-based approach enforced a quality assurance cycle as a key component of this reform. Many teachers in the focus groups described the standards-based curriculum as interesting since it incorporated various strategies and fostered creative expression among students and teachers alike. This was considered a key distinguishing feature attributed to a standards-based curriculum in contrast to textbook-based curriculum. The standards-based curriculum required teachers to select strategies, develop content, and choose various resources, as a result of which teachers were driven to research effective pedagogical practices and deliver lessons in an engaging manner. A teacher noted:

If the standards required the student to identify the story elements, for example, and if the student was talented in drawing, then they did not have to only write down the elements, rather, they could draw these.

The challenges facing teachers implementing the standards-based approach revolved around two themes:

(1) The number of performance indicators under each standard they were required to teach. Several teachers commented on the number of standards they were expected to cover in each academic year and felt that these were too many. They said that there were 50 performance indicators to cover per academic year and 
that these were difficult to accommodate. They also noted that the standards were repeated during many lessons, which resulted in students feeling bored. However, other teachers reported that repetition of standards positively impacted student learning because it helped identify students' strengths and weaknesses and the required interventions.

(2) Expectations emanating from the standards.

a. There were too many skills students were expected to acquire and teachers could not impart these in a consistent and reliable manner.

b. There was an over emphasis on skill development at the expense of knowing and understanding content.

c. The absence of memorization skills resulted in poor retention of learned material for creativity.

d. The standards were above the students' level of understanding. In fact, some students got confused, and some teachers could not achieve the desired standards.

e. Teachers felt that the progression of the standards was unclear to them.

\subsection{The standards-based curriculum and content variations}

During the implementation of the standards-based curriculum, teachers used the Ministry of Education (MoE) textbooks and relied on other resources of their choice. These resources were provided by ADEK and covered material for leveled readers and highquality children's literature. Teachers were encouraged to select multiple texts that addressed a particular skill. The availability of textbooks was good for those teachers who did not receive support on teaching the new curriculum.

Owing to the unprecedented autonomy granted to teachers in content selection, a teacher might have taught a certain text in Grade 1 while another might have taught it in Grade 5. Some teachers, participants argued, did not make an effort to carefully select the content that ensured student comprehension. One of the challenges faced was that the textual level that students ought to access at their respective ages was not determined or clearly stated. For example, for students in Grade 1, it is important that texts include diacritical marks or vowelization known in Arabic as harakat, without which these students would face great difficulty reading texts. Therefore, if a teacher downloads a text bereft of diacritical marks from the Internet, and if they are not qualified to add the correct diacritical marks to the text, then reading for students becomes 
problematic, and their fluency slowed down, especially in lower primary grades. Certain texts selected by teachers might also not have been relevant to the culture of the UAE; a teacher argued:

Some of the stories were borrowed from the West, including names which were difficult to pronounce.

Some teachers recalled the times before the advent of the standards-based movement when they used a prescribed MoE textbook that, they claimed, granted them a fixed curricular mold and a consistent routine. Teachers were forced to teach lessons as prescribed by the textbook. They were required to finish teaching the textbook by a certain date, regardless of the lessons' suitability for students or without necessarily catering to the varying student levels, since the focus was on quantity alone. The result manifested itself in producing the same output or product-students who could not think for themselves and perfunctorily answered the end-of-year summative examination questions. Participants explained that it was common for students to complete exercises in their textbooks without necessarily achieving the objectives of the exercise. Teachers described the textbook-centered approach as boring because of its repetitive pattern. Because it was static and fixed, it did not allow them to interact with social and national cultural events. However, the textbook-centered approach was commended for its strong focus on the affective knowledge and values of citizenship and national belonging through its inculcation of patriotism.

Participants complained about the lack of unified content or content guidelines along with the misalignment of assessments as some of the main challenges faced during the implementation of the standards-based curriculum. Teachers noted, students often got confused owing to the lack of unified content, especially during preparations for examinations; there was no specific material for students to study. This was aggravated with the misalignment between the central examinations and the standards-based teaching approach along with the absence of a unified assessment framework. A teacher articulated the challenge of the lack of rigor in assessment as:

Students passed each grade level by default and this contributed to weakening of the level of students, particularly at lower primary levels. Some students reached grade four not knowing the alphabet.

As a result, students were not necessarily good at test-taking, although the standardsbased approach honed their skills. It was up to the teacher to determine whether the standard was achieved. Some teachers did not make an effort to assess the standards 
particularly because there were no instruments for assessment that went with the learning outcomes.

\subsection{The teacher and the standards-based curriculum}

Teachers noted that they developed knowledge, skills, and competencies during the implementation of the standards-based model in multiple ways. For example, the teachers became accustomed to the cooperative planning process and working in teams rather than individual planning. Teachers also described their growth in terms of learning more about teaching strategies. The strategies they mentioned included guided reading, role-play, drawing in storytelling, incorporating music, acting out vocabulary, computer search, use of library resources, utilizing the "six hats" strategies, and thinking keys. Additionally, Kagan structures and the use of learning corners such as the research corner, the reading corner, the writing corner, and the problem-solving corner. A teacher described her application of the project-based approach as follows:

We employed project-based learning a lot more wherein students would work collaboratively on a project. For example, in one year, a project entailed planting the garden areas in the schoolyard. Through the implementation of this project, we applied many of the standards that were required of Grade 5 students.

Teachers also developed their skills since they had to look for content that would help them achieve the particular standards that are age and cognitively appropriate. However, many teachers viewed the process of selecting the content as a challenge because they had to research extensively to select suitable content. It was akin to teachers developing the curriculum and creating all the activities and exercises as well. A teacher critiqued the situation because:

The teacher became tasked with the roles of being a teacher, an author, and a researcher which were too many and challenging.

Another teacher added:

The teacher needed to search for resources and to create activities that cater to different needs. We also needed to create projects and conduct ongoing formative assessments and connect the language themes with the subjects of English, math, and science. 
The participants noted that the teacher needed to have a high level of mastery in various teaching methods. Moreover, they noted that the curriculum was teacherdependent in that students' learning became dependent on the proficiency of the teacher. It was noted that some teachers taught the standards at a superficial level; thus, students' learning was compromised.

\subsection{The student and the standards-based curriculum}

According to teachers, the main strength of the Arabic standards-based curriculum was that it emphasized the basic skills of reading and writing in a reiterative process. The outcomes were clear, and teachers were able to identify the students' areas of weakness precisely and bridge the gap between the students' level and the required standard. Teachers also observed that the students made continuous progress based on their level regardless of their abilities. This was reflected in a teacher's view of the curriculum as being one that "focuses on quality rather than quantity." The standards' focus on reading and writing skills in a comprehensive manner meant that students had a wider scope to write because they were able to elaborate and explain their ideas. Teachers also noted that the curriculum delivered language skills such as grammar and spelling in an easy manner.

Among students' abilities that were improved was analyzing and deriving conclusions from reading the texts. The $21^{\text {st }}$-century skills acquired by students through the standards-based curriculum included problem-solving, communication, creativity, cooperation, and leadership. Teachers mentioned that many students became linguistically creative, which meant that they had mastered reading, writing, and comprehension and were able to utilize some tools of creative expression. Teachers observed that students' personalities were further developed as a result of implementing this curriculum. Students gained self-confidence, took responsibility for and ownership of their learning, and learned to work independently. Students were also encouraged to speak and write extensively, which helped them better express themselves.

The knowledge students gained through the standards-based curriculum was described to be transferrable, according to a teacher:

When students learn the skill of identifying and using synonyms, they don't necessarily need to identify the words in the paragraph that they have studied before the teacher. Rather, they are able to identify this feature 
in any text. This is a good gain for the student because the approach of the curriculum is to teach students how to fish rather than giving them a fish.

Another teacher added:

With the previous curriculum, when the student was exposed to a text that was different from the one that was taught in the textbook, the student would not be able to identify key features in a text. However, in this curriculum, students who are used to being exposed to different texts and applying the skills for studying these will be able to do well in any exam.

These gains in student achievement were often attributed to the flexibility of the curriculum that accommodated differences. Teachers had the flexibility to focus on students' weaknesses and individual needs. Students received instructions that suited their levels since the teacher would carefully select the content that met each student's level. Consequently, teaching was student-centered, as one teacher noted:

We could focus on students' weaknesses in, for example, sounding out words, summarizing, or spelling. The student outcome became better because the students read while the teachers monitored precise objectives and ensured fluency in addition to comprehension.

Another teacher reflected:

Students have excelled in different areas. We got a student who excelled in reading, another who excelled in speaking, and yet another who excelled in drawing and so on. Therefore, not only were the outstanding students recognized but rather every student excelled in one or the other aspect of learning in the classroom.

\section{Discussion}

The low performance of Arab students on international literacy tests has been a topic of extensive discussion in the Arab world. Therefore, standards-based instruction has been adopted in a few Arab countries in the past decade to transform Arabic teaching and learning. Such initiatives ought to be studied closely to build on the successes, bridge the gaps, and avoid the failures as countries, systems, and schools progress in their endeavors of improving the acquisition of Arabic, the first language, for students in the Arab world. Besides the narrative feedback, implementing the standards-based Arabic 
curricular initiatives in the Arab countries has not been investigated systematically. This study aimed to derive the key lessons from a unique case of implementation that offers insights that could inform future studies and reform existing policies. This study utilized a qualitative purposeful sampling to collect data on the implementation of the standardsbased Arabic curriculum in schools in Abu Dhabi.

This section is arranged under three themes that synthesize the findings of the study in relation to teacher perceptions, the taught content, the impact on teachers, and that on students. The themes in this section are as follows: (1) teachers' perceptions of the standards-based curriculum, (2) key teacher-reported successes, and (3) key teacherreported challenges."

\subsection{Teachers' perceptions of the standards-based curriculum}

Teachers in this study reported that the adoption of the standards-based curriculum acted as a catalyst for them to grow in knowledge, skills, and competencies. Arabic teachers in Abu Dhabi were positive about the standards-based Arabic curricular reform as they confirmed its purposefulness, relevance, and high quality. Similarly, regarding Washington State's educational reforms, Stecher et al. (2000) stated that most teachers reported that reforms contributed to better teaching and learning. Arabic teachers also observed and confirmed positive student learning outcomes, lending support to the efforts of Arab countries to transform Arabic teaching and learning and to research that argues for the positive impact of the standards-based movement (Carnoy \& Loeb, 2002; Stecher et al., 2000).

In the case of standards-based curricular experience in the United States, there has been an apparent dichotomy between standards-based teaching where teachers were focusing on directing student learning toward a common predetermined standard and differentiation. This also resulted in many teachers rushing to cover the standards. Tomlinson (2000) states that this dichotomy can be reconciled by understanding that differentiation shows us how to teach the same standard to different learners by employing various teaching and learning modes to avoid the pitfalls of the one-size-fitsall curriculum. This perception was well reflected in the observation of Arabic teachers in Abu Dhabi, who believed that the shift from the textbook-based curriculum to the standards-based model promoted differentiation and was essential to the studentcentered learning approach.

Extant research on literacy acquisition in Arab countries has concentrated on the unique characteristics of the Arabic language and the implications of its orthographic 
and diglossic features on acquisition of reading skills while neglecting the effects of students' motivation (Ferguson, 1959; Yang et al., 2018b). The fact that teachers, as mentioned in the study, reported that students considered the standards-based mode of instruction of Arabic interesting is also consistent with one of the fundamental tenets of the standards-based reform that teachers ought to engage students (Stecher et al, 2002; Tomlinson, 2000). As students' extrinsic motivation for reading works effectively in the Abu Dhabi context (Yang et al., 2018b), the standards-based approach in Arabic learning has the potential to enhance students' intrinsic motivation and performance for reading through the provision of interesting and stimulating reading tasks and aligning motivational support with differentiated instructional practice (Guthrie et al., 2006).

\subsection{Key teacher-reported successes}

Participants in this study also reported several positive effects of standards-based instruction, which included students becoming more skillful and confident, teachers becoming empowered and autonomous, and the teacher planning process more collaborative. A sustainable improvement of literacy ought to be based on the interdependent relationship between the school structures, leadership, and agency targeting the instructional core (Francois, 2012). This study's findings are consistent with teachers' emphasis on autonomy as a main advantage of the standards-based language curriculum. As teacher autonomy and influence in the UAE's public schools remain weak (Troudi \& Alwan, 2010), a standards-based approach may help boost teacher morale. The contribution of autonomy to the increase of teachers' commitment is supported by studies conducted in the context of Abu Dhabi (Yang et al., 2019). Alternatively, the factors of success identified by this research supports the argument that an enabling school environment consisting of high levels of transformational leadership, teacher collegiality, and supportive relationships is conducive to teachers' commitment and effectiveness (Day \& Gu, 2010; Fransson \& Frelin, 2016; Yang et al., 2018a). Moreover, such an enabling school environment helps reinforce students' emotional and cognitive engagement with school and learning (Yang et al., 2017). 


\subsection{Key teacher-reported challenges}

While Arabic teachers described the implemented curriculum in Abu Dhabi to be purposeful, relevant, and engaging; it was also considered challenging. Teachers' challenges included the large number and wide scope of performance indicators, the vast range of skills that needed to be covered, the limited scope for memorization, and the lack of clarity on the standards progression. Indeed, too many prescriptive documents on standards and indicators may frustrate teachers' attempt to provide common focus (Wilson \& Bertenthal, 2006). Therefore, one of the policy implications of this study is that the anticipated success of the standards-based reforms must be based on the establishment of clear, coherent, but not exhaustive standards organized around key skills and strategies.

\section{Limitations}

A limitation of this study lies in the selective sampling of outstanding teachers who mastered the curriculum. This sampling approach was adopted in line with the aim of this study. Despite this limitation, the proposed methodology enabled the collection of valid data on the accumulated experiences and the lessons learned by teachers. These teachers had an opportunity to effectively implement the standards-based Arabic curriculum across schools in the city of Al Ain and the rural and urban areas of the city of Abu Dhabi.

\section{Conclusion}

The whole concept of standards-based instruction centers on having clear goals or performance indicators that are unified across educational districts, teachers, and schools. Standards give administrators, teachers, and parents one common language though which they can communicate clearly and transparently. This study focused on the ADEK's experience with implementing a standards-based model in the schools they oversee. Arabic language teachers interviewed in this study had a generally favorable opinion of the standards model and hailed it as a model that allowed them unprecedented autonomy. Teachers, in addition, highlighted the rigor, engagement, and relevance of such a model to them and their students. Standards-based instruction almost forced the teachers to find solutions to challenges of implementation by collaborating with each other and helping each other find interesting texts and content that 
can be used in the classroom. Teachers, additionally, mentioned that the standardsbased instruction model they implemented helped ignite higher-order thinking skills in students and student improvement was a key finding

However, apart from the standards of content, the standards movement that aimed to teach more challenging curricula to students, requires substantial, if not fundamental, changes in instructional practices, capacity building, and teachers' professional development. These are the essential components of standards-based reforms. While these have been largely adopted in Abu Dhabi's educational reformation, policy-makers in the UAE ought to consider the needs and the barriers perceived by teachers in order to provide effective professional development training to teachers (Badri et al., 2016). Additionally, a necessary and important step is to develop a national program of evidence-based assessments to evaluate learning progressions. A standards-based model to Arabic language instruction might only be a first big and exciting step in a long yet fascinating journey of excellence and innovation in Arabic language teaching and learning.

\section{Author Contributions}

The study was developed by the three authors. All authors contributed collaboratively to the design of the work and the analysis and interpretation of data. Each author drafted certain sections of the manuscript. The manuscript was reviewed and approved by all authors prior to submission.

\section{Acknowledgements}

The authors wish to thank all participating schools, teachers, and administrators who have been so supportive of this research.

\section{Funding Information}

This work was supported by the Zayed University Cluster Grant, number R18024. The funding source did not contribute to the research and writing of the article.

\section{Competing Interests}

The authors have no competing interests to declare. 


\section{Author Biographies}

Dr Mariam Alhashmi is an assistant professor in the College of Education at Zayed University, UAE. Her academic interests include Arabic language teaching and its implications for curriculum development and professional learning for teachers. She has extensive expertise in international education, teachers' professional development, and Islamic and Arabic education. Prior to joining Zayed University, she successfully led curricular development across 20 Emirates National Schools as the Director of Curriculum and Instruction and trained over a thousand teachers and principals in the UAE, Kuwait, Saudi Arabia, and Kenya.

Dr Hanada Taha-Thomure is the endowed professor of Arabic Language and Director of the Arabic Language Center for Research \& Development at Zayed University, UAE. Previously, she served as Acting Dean of Bahrain Teachers College, University of Bahrain, where she joined as Associate Dean in 2010. She has close to 30 years of experience in teacher preservice preparation and in-service training, Arabic Language curriculum design, developing and reviewing national literacy strategies, and literacy coaching. She designed the first system for levelling Arabic texts, which is currently used by regional and international publishers to level Arabic children's books. More than 8000 books have been levelled free of charge with a grant from the Arab Thought Foundation. Dr Taha-Thomure is the senior author of the Pearson's first Arabic language Arts K-9. Her research is in the fields of Arabic language teaching and learning, Arabic children's literature, and teacher preparation. She holds a PhD in Education from the University of New Orleans (2001).

Dr Karima Almazroui is the advisor to chancellor of Mohamed bin Zayed University for Humanities. She was the chairwoman and founder of the Educators without Borders NGO, based in Geneva, and the founder and chairwoman of the Abu Dhabi Reads Campaign 2013. Dr Karima acted as an executive director for P-12 Education in Abu Dhabi, her responsibilities in the Department of Education and Knowledge included education policy design, education planning, curriculum design, teachers' licensing, and special education (McDonnell, 2004). At the national level, she led teams to author national Arabic language curriculum, publishing more than 30 books based on Arabic language standards. She presented the crown prince of Abu Dhabi with the Moral Education curriculum that is now used at national level. In addition, she presented projects to the Ministry of Education, Ministry of Tolerance, and Ministry of Culture. She served as a member of the Board of Trustees in the Emirates College for Advanced Education and Mohamed the Fifth University. Dr Almazroui has worked as an associate professor in the United Arab Emirates University, with over 30 publications and 3 books 
(two of which are taught in the university). Dr Almazroui holds a Ph.D. in language, reading, and culture under the supervision of Yetta Goodman from the University of Arizona. She was awarded the Middle East Women Leaders in Education 2016.

\section{References}

[1] ADEK Website (2021). Irtiqaa program - Improving schools' performance. Retrieved from https://www.adek.gov.ae/Education-System/Private-Schools/IrtiqaaProgramme-Improving-Schools-performance

[2] Badri, M., Alnuaimi, A., Mohaidat, J., Yang, G., \& Al Rashedi, A. (2016). Perception of teachers' professional development needs, impacts, and barriers: The Abu Dhabi case. SAGE Open, 6(3), 1-15. https://doi.org/10.1177/2158244016662901

[3] Barlow, A. (2012). Transitioning to standards-based instruction: Beliefs and views of an elementary mathematics teacher. Teaching \& Learning, 26(1), 3-19.

[4] Carnoy, M., \& Loeb, S. (2002). Does external accountability affect student outcomes? A cross-state analysis. Educational Evaluation and Policy Analysis, 24(4), 305-331.

[5] Carr, J. F., \& Harris, D. E. (2001). Succeeding with standards: Linking curriculum, assessment, and action planning. Association for Supervision and Curriculum Development.

[6] Chambers, L., \& Dean, C. (2000). Noteworthy perspectives on implementing standards-based education. Mid-continent Research for Education and Learning. Retrieved from http://files.eric.ed.gov/fulltext/ED460977.pdf

[7] Creswell, J. W. (2009). Research design: Qualitative, quantitative, and mixed methods approaches. SAGE.

[8] Day, C., \& Gu, Q. (2010). The new lives of teachers. Routledge.

[9] Faour, M. (2012). The Arab world's education report card: School climate and citizenship skills. Carnegie Endowment for International Peace. Retrieved from http://carnegieendowment.org/files/school_climate.pdf

[10] Ferguson, C. A. (1959). Diglossia. Word, 15(2), 325-340.

[11] Francois, C. (2012). Getting at the core of literacy improvement: A case study of an urban secondary school. Education and Urban Society, 46(5), 580-605.

[12] Fransson, G, \& Frelin, A. (2016). Highly committed teachers: What makes them tick? A study of sustained commitment. Teachers and Teaching, 22(8), 896-912.

[13] Gibbs, A. (1997). Focus groups. Social Research Update, 19(8), 1-8.

[14] Guthrie, J. T., Wigfield, A., Humenick, N. M., Perencevich, K. C., Taboada, A., \& Barbosa, P. (2006). Influences of stimulating tasks of reading motivation and comprehension. Journal of Educational Research, 99(4), 232-246. 
[15] Halladay, J. L., \& Moses, L. (2013). Using the Common Core Standards to meet the needs of diverse learners: Challenges and opportunities. New England Reading Association Journal, 49(1), 33-44.

[16] Hanushek, E., \& Raymond, M. (2005). Does school account ability lead to improved student performance? Journal of Policy Analysis and Management, 24(2), 297-327.

[17] Hussein, A. (2014). The indicating factors of oral fluency of monolingual and bilingual children in Egypt. International Education Studies, 7(2), 75-90. https://doi.org/10/5539/iesv7n2p75

[18] Karoly, L. A. (2010). The role of education in preparing graduates for the labor market in the GCC countries. Rand Corporation.

[19] Litosseliti, L. (2003). Using focus groups in research. A\&C Black.

[20] McDonnell, L. M. (2004). Politics, persuasion, and educational testing. Harvard University Press.

[21] Merriam, S. B. (2009). Qualitative research: A guide to design and implementation. Jossey-Bass.

[22] Morgan, S. P. (2017). Is common core 'working'? And where does common core research go from here? AERA Open 3(1), 1-6. https://doi.org/10.1177/2332858417691749

[23] Mullis, M. F., \& Arora, A. (2012). Trends in International Mathematics and Science Study (TIMMS) 2011 international results in reading. International Association for the Evaluation of Educational Achievement. Retrieved from https://timssandpirls.bc.edu/ timss2011/downloads/T11_IR_Mathematics_FullBook.pdf

[24] Mullis, I. V., Martin, M. O., Foy, P., \& Drucker, K. T. (2012) PIRLS 2011 International results in reading. TIMSS \& PIRLS International Study Center, Lynch School of Education, Boston College and International Association for the Evaluation of Educational Achievement (IEA), IEA Secretariat. Retrieved from https://timssandpirls.bc.edu/pirls2011/downloads/P11_IR_FullBook.pdf

[25] National Research Council. (2008). Common standards for K12 education: considering the evidence. The National Academies Press.

[26] Ogawa, R. T., Sandholtz, J., \& Scribner, S. (2004). Standards gaps: Unintended consequences of local standards-based reform. Teachers College Record, 106(6), 1177-1202.

[27] Ornstein, A. C., \& Hunkins, F. P. (2017) Curriculum: Foundations, principles, \& issues. Pearson.

[28] Polikoff, M. S., Hardaways, T., \& Marsh, J. A. (2016). Who is opposed to common core and why? Educational Researcher, 45(3), 263-266. 
[29] Porter, A. C., Polikoff, M. S., \& Smithson, J. (2009). Is there a de facto national intended curriculum? Evidence from state content standards. Educational Evaluation and Policy Analysis, 31(3), 238-268.

[30] Reeves, D. B. (2004). Making standards work. Advanced Learning.

[31] Salama, S. (2016, November 1). Reading law opens a new chapter in UAE. Gulf News. https://gulfnews.com/uae/government/reading-law-opens-a-newchapter-in-uae-1.1922410

[32] Stecher, B., \& Borko, H. (2002). Integrating findings from surveys and case studies: Examples from a study of standards-based educational reform. Journal of Education Policy, 17(5), 547-569.

[33] Stecher, B., Chun, T., \& Ross, K. (2000). The effects of the Washington state education reform on schools and classrooms (Publication No. 525). The Regents of the University of California. Retrieved from https://cresst.org/wpcontent/uploads/TECH525.pdf

[34] Stewart, D. W., Shamdasani, P. N., \& Rook, D. W. (2000). Focus groups: Theory and practice. SAGE.

[35] Taha-Thomure, H. (2008). The status of Arabic language today. Journal of Education, Business and Society: Contemporary Middle Eastern Issues, 1(3), 186-192.

[36] Taha-Thomure, H. (2017). Arabic language teacher education. In A. Gebril (Ed.), Applied linguistics in the Middle East and North Africa (pp. 267-287). John Benjamins.

[37] Taha-Thomure, H. (2019). Arabic language education in the UAE. In K. Gallagher (Ed.), Education in the UAE: Innovation and transformation (pp. 75-93). Springer. https://doi.org/10.1007/978-981-13-7736-5_5

[38] Taha-Thomure, H., \& Sabella, T. (2015). Assessment \& curriculum: A 10-year policy plan for Jordan. Queen Rania Foundation.

[39] Taha-Thomure, H., \& Speaker, R. (2018). Arabic language arts standards: Revolution or disruption? Research in Comparative and International Education, 13(4), 551-569.

[40] Tomlinson, C. A. (2000) The differentiated classroom: Responding to the needs of all learners. Association for Supervision and Curriculum Development.

[41] Troudi, S., \& Alwan, F. (2010). Teachers' feelings during curriculum change in the United Arab Emirates: Opening Pandora's box. Teacher Development, 14(1), 107-121.

[42] UNESCO. (2017). Literacy rates continue to rise from one generation to the next: Fact Sheet No. 45. UNESCO.

[43] United Arab Emirates Ministry of Culture and Youth. (2020). Arabic language status and future report (Arabic). Ministry of Culture and Youth, UAE.

[44] Wilson, M. R., \& Bertenthal, M. W. (2006). Systems for state science assessment. National Academies Press. 
[45] World Bank. (2004). Unlocking the employment potential in the Middle East and North Africa: Toward a new social contract. World Bank Publications.

[46] World Bank. (2021). Advancing Arabic language teaching and learning: A path to reducing learning poverty in the Middle East and North Africa. Washington, DC: World Bank.

[47] Yang, G., Badri, M., Al Rashedi, A., Almazroui, K., Qalyoubi, R., \& Nai, P. (2017). The effects of classroom and school environment on student engagement: The case of high school students in Abu Dhabi public schools. Compare: A Journal of Comparative and International Education, 47(2), 223-239.

[48] Yang, G., Badri, M., Al Rashedi A., \& Almazroui, K. (2018a). The social and organisational determinants of school commitment of expatriate teachers. Journal of Research in International Education, 17(1), 33-48.

[49] Yang, G., Badri, M., Al Rashedi A., \& Almazroui, K. (2018b). The role of reading motivation, self-efficacy, and home influence in students' literacy achievement: A preliminary examination of the fourth graders in Abu Dhabi. Large Scale Assessments in Education, 6, 10. https://doi.org/10.1186/s40536-018-0063-0

[50] Yang, G., Badri, M., Al Rashedi A., \& Almazroui, K. (2019). Predicting teacher commitment as a multi-foci construct in a multi-cultural environment: The effects of individual, school, and district level factors. Teachers and Teaching: Theory and Practice, 25(3), 301-319.

\section{Appendix A}

\section{Focus Group Questions}

- What is a standards-based curriculum?

- How is it different from a textbook-based curriculum?

- What in it affected student achievement positively?

- What in it affected student achievement negatively?

- What did you find easiest in implementing the curriculum?

- What was the most challenging part in implementing the curriculum?

- How did you teach differently following the implementation of the standards-based curriculum?

- How did you benefit professionally from the shift to a standards-based curriculum? 
-What training programs on the standards-based curriculum did you participate in?

- Would you like to teach the standards-based curriculum again? Why? 